\title{
Development of A Water Supply Scheme with Reference to the Ampara Project
}

\author{
Ananda Ranasinghe
}

Abstract: Every living creature needs clean and safe drinking water. How much do you need? It depends - your size, activity level and the weather, all make a difference.

The water you drink is a combination of surface water and groundwater. Surface water includes rivers, lakes and reservoirs. Groundwater comes from underground. Presently it is hard to find clean supplies and water quality can vary from place to place. It depends on the condition of the source water and the treatment it receives. Treatment may include screening, filtering, chemical dosing, adding fluoride and chlorine to kill germs.

There is no such thing as naturally pure water. Naturally, all water contains some impurities. As water flows in streams, sits in lakes, and filters through layers of soil and rock in the ground, it dissolves or absorbs the substances it touches. Some of these substances are harmless. In fact, some people prefer mineral water precisely because minerals give it an appealing taste. However, at certain levels, minerals, just like man-made chemicals, are considered contaminants that can make water unpalatable or even unsafe. Some contaminants come from erosion of natural rock formations. Other contaminants are substances discharged from factories, applied to farmlands or used by consumers in their homes and yards. Sources of contaminants might be in your neighborhood or might be many miles away. Therefore, in spite of its availability in abundance, water has to be treated for human consumption and this could be costly.

Drinking water treatment plants, sewer lines, drinking water distribution lines, and storage facilities ensure protection of public health and the environment. As a nation, we have built an extensive network of infrastructure to provide the public with access to water and sanitation. Therefore it is a challenge for the engineer to design and construct feasible schemes keeping the cost to a minimum. In this project the designers have taken the challenge of designing most of the structures in nontraditional manner to expedite construction and to optimize the construction cost..

\section{Introduction}

Infrastructure is a measure of development and advancement by the mankind. It has evolved with the civilisation of the mankind. Therefore infrastructure plays the main role in the development of a country as it directly affects the livelihood and social wellbeing of the people. Development of infrastructure is as old as the existence of the mankind and it has been a challenging task for the engineers to improve infrastructure as society demands have also expanded proportionately with the expansion of the population. Drinking water is one of the most important infrastructure facilities developed by human beings. The quest for water began with the development of the human civilization. Most of the human civilizations were founded within the proximity of rivers as water had been the lifeblood of all human beings and animal life.
However, with the development of industry, using water in its natural state was impossible since it had been contaminated and polluted by various sources. The sources of contamination are discharges from factories, utilization of chemical fertilizers, oil spillage, discharge of various by-products, extraction of excessive water etc. Therefore it is essential that all water extracted from natural resources has to be purified for human consumption.
Eng. Ananda Ranasinghe, BSc Eng.(Hons), MTech, AIStructure, MIE(Aust), MICE(UK), CEng, FIE(Sri Lanka), Attorncy-Law, Consulting Engineer 


\section{Policies of the State}

In Sri Lanka, the National Water Supply \& Drainage Board, as the main organization for planning, developing, commissioning and distributing water in the country, is responsible for the provision of clean pipe borne water to the general public. Generally, water is extracted from rivers, reservoirs and sometimes from deep wells constructed at suitable locations. Presently there are many water supply schemes constructed by the National Water Supply \& Drainage Board which maintains and distributes water through some of the water supply schemes while others are maintained by local authorities.

In spite of many water supply schemes in Sri Lanka, more than $70 \%$ of the population still do not have access to pipe borne water and of the $30 \%$ population given the facility, a fair proportion still does not get an uninterrupted supply.

In Sri Lanka, we have a national policy on water supply and the main objective of this policy is to ensure access to clean drinking water and proper sanitation to the entire population by the year 2025. Apart from this, the policy is also directed at achieving the following objectives:

i.). To provide clean water to at least $85 \%$ of the population through pipe borne water or by bore hole wells, dug wells or rain water by the year 2015.

ii.). To improve the quality of service by the National Water Supply \& Drainage Board and to maintain high standards in view of achieving national goals.

iii.). To provide sufficient sanitation facilities to a population of more than $80 \%$ by providing sewerage systems, latrines etc

iv.). To meet the increased demand created by the expansion of industry and other economic sectors.

v.). To provide technical input for local government institutions and community organizations to assist in the implementation of water supply and sanitation facilities. vi.). To provide water management such as surface water drainage and to make use of storm water for drinking puroses.

vii.). To encourage community participation in water supply schemes at appropriate levels.

Therefore, most of the features listed above which necessitate the development of water resources, have been adopted in water supply schemes implemented by the National Water Supply \& Drainage Board.

In order to facilitate this process and in order to provide clean drinking water without impurities, it has been the practice in water supply schemes to construct plants to purify water before distribution for human consumption.

\section{Development of the Scheme}

The water supply scheme which was implemented in Ampara to feed the eastern coastal towns also has similar features. This project came into operation in the year 2004 where the National Water Supply \& Drainage Board, in collaboration with Ottokumpu Australia (Pvt) Ltd., of Australia, did the planning, designing and construction to supply water for a population of nearly 750 thousand in the eastern coastal towns. Although this project consisted of two phases, a proposal was submitted to have an extra phase to provide drinking water to an extended arca. Some of the townships that came under this project were Ampara, Irakkamam, Bangalawadiya, Sammanthurai, Oluvil, Karaitivu, Sainthamaruthu and Maruthamunai.

\section{Design of the Scheme}

It is extremely important that water supply infrastructure, or for that matter any other infrastructure, should have the features of simplicity, reliability, adaptability and cost effectiveness. Complicated designs could lead to errors and also sophisticated equipment could have maintenance problems as we do not have skilled technicians to meet such crises. Therefore, simplicity in design is an essential factor. Furthermore, when the water supply scheme is commissioned it should be easily 
operable and also should not have a major impact on the environment. In designing water supply projects, one should pay attention to all components of the project. Diversion of water, storage, regulating and distribution of water are important aspects.

In Phase I of the project there were many civil engineering structures such as water pumps, water towers and a pipe distribution system. There were six water tanks constructed in Phase II of this project in capacities varying from 750 cubic metres to 1,600 cubic metres. The elcvation of these tanks also varied from 22 $\mathrm{m}$. to $25 \mathrm{~m}$. Water for this scheme was drawn from the Kondawatuwana Tank and a treatment plant adjacent to this tank was constructed with the capacity to pump 16 million gallons of water per day. This treatment plant has two clear-water tanks, high-lift pump house, sludge-holding tank, sludge thickener, filters and a service water tower.

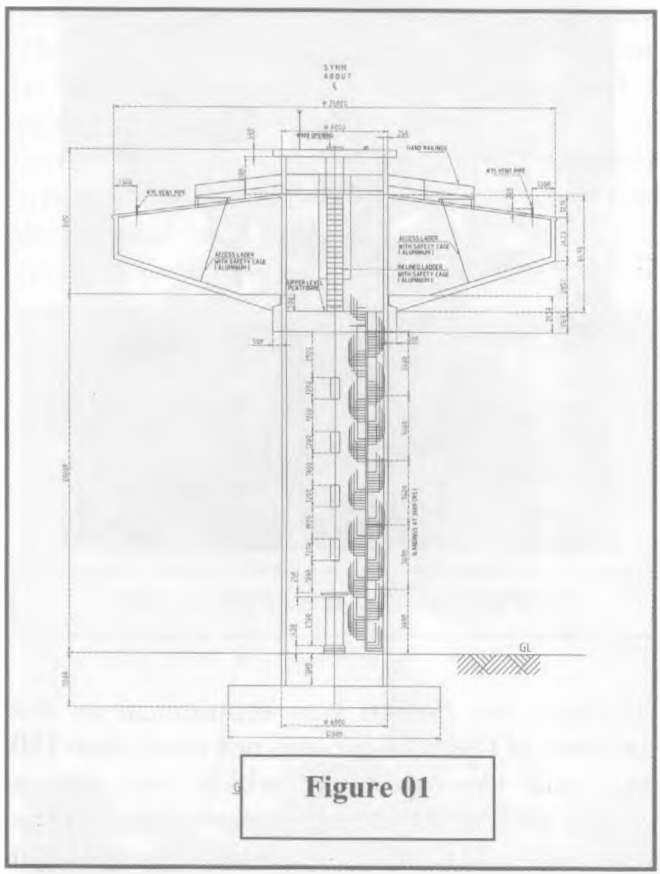

As there were many structures in this project, this paper intends to emphasise on structural design and construction of water towers which were especially designed for this project, bearing in mind the extra heights that were necessary to obtain the required water pressure for distribution purposes and other reinforced concrete structures. A typical drawing of the water tower is given in Fig. 1.

\section{Construction Process}

The diameters of these tanks were extended up to $18 \mathrm{~m}$. As it was very important to maintain the quality of concreting, it was decided to construct these tanks at the ground level. Therefore a method had to be conceived by the Structural Engineers to lift these tanks up once they were completed at the ground level and to fix them firmly at the required elevations so that whilst maintaining stability, water is retained without any possible leakage.

Initially, the Structural Engineers concentrated on designing a suitably shaped tower so that lifting of the tanks could be done without any hindrance. It was decided that a circular shaped tower with a reasonable diameter would serve this purpose. As it was necessary to standardize the size of the tower so that whatever equipment used for lifting the tank could also be standardized in view of minimizing the cost of lifting, a diameter of size $6 \mathrm{~m}$ was decided on as practical for the purpose. It was also a requirement that the tower should resist lateral wind loading which was considered as 75 metres per second. Further to this the tower was also designed to resist vertical loads acting on the tower as well as the tank. The Structural Engineer also had to face the challenge of designing a tower to accommodate a feasible arrangement to lift the water tank up to the required level. In order to facilitate this, a vertical tower was designed with a thick concrete lid at the top so that jacks could be used against this section to lift the water tanks.

After construction of the centre tower, the tank was built around the tower at the ground level. Construction of the water tank had been quite fast and economical as the formwork was done at the ground level and pouring of concrete had been quite easy. Thereafter the tanks were lifted to the required level and anchored firmly using concrete corbels. To lift the water tank eight cables were used around the periphery of the centre core thereby distributing the lifting load evenly on the jacks. The jacking system was controlled by a synchronized arrangement so that the lift at every stage could be maintained evenly on all sides thus preventing high eccentric and uneven loading on jacks due to possible tilting of the tank. The top cover mentioned earlier was designed for placing the 
jacks and also to carry the concentrated load weighing approximately $1 / 8$ of the total self wcight of the completed water tower. It was also anticipated that whilst lifting the tank could sway due to the high wind velocities and therefore a further allowance was made in designing the water tower to take this unbalanced loading as well.

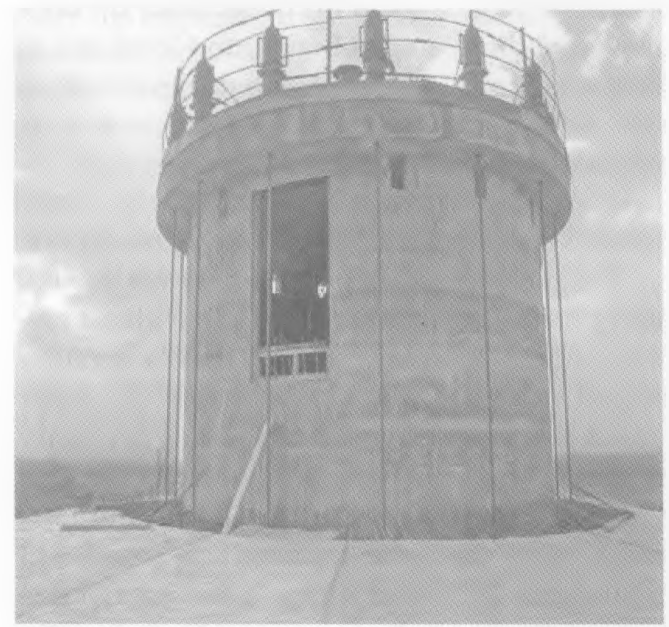

LIFTING ARRANGEMENT OF THE TANK

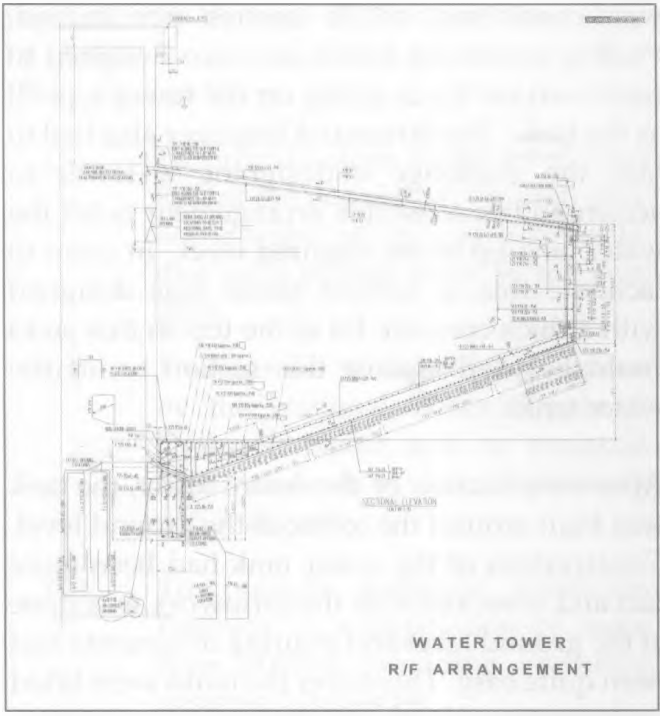

Figure 2

The construction Engineers were also of the view that the bottom and top covers of these water towers should be reasonably flat so that they could cast these slabs without formwork on either side. This was proposed by the construction Engineers as they believed that if they can have direct access to one face during concreting, they could vibrate from this face and minimize the honeycombing effect thus maintaining very high quality concrete. Therefore a slope of 1:5 had to be used for the top cover and 1:3 for the bottom slab. A typical detail section of the tank is shown in Fig. 2.

The clear water tanks of this project used to collect purified water are circular in shape and 15 mtrs in diameter. The top cover was designed as a shell roof. The shape of the tank being circular, the walls of the tanks were also designed as a cylindrical shell, and the Structural Engineer did not fix the tank at the bottom but allowed it to slide so that no moment was created at the bottom of the tank. This simplified the construction procedure and also economized on the design to a certain extent. The base was separated from the tank and it was just laid on the ground with a water tight connection to the foundation of the cylindrical wall.

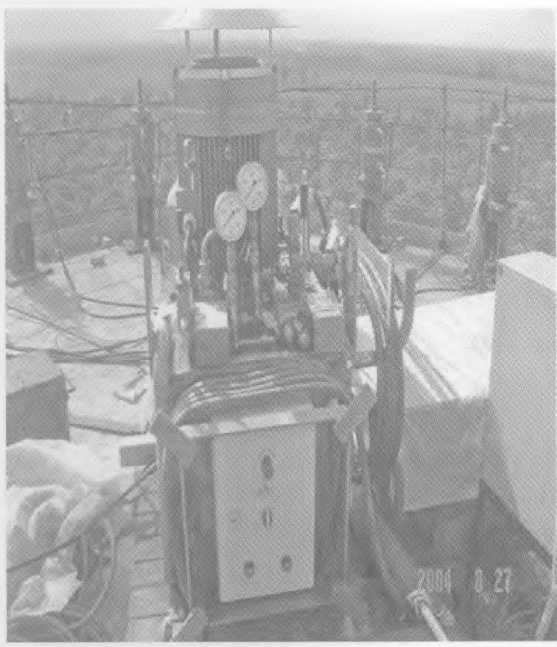

SYNCHRONISED JACKS IN POSITION

Although this design was economical as the thickness of the cylinder was not more than 150 mm., and the top cover which was also a circular shell of $100 \mathrm{~mm}$ thickness except at the edges where it was increased to a depth of 200 $\mathrm{mm}$, there were disadvantages as it was separated from the base slab. Therefore whatever groundwater pressure that was created externally could lift the base slab since it was a separate structure from the cylindrical tank. During the construction, there were problems when emptying the tanks after heavy rains as the base slab tended to lift. However, this design miscalculation was corrected later. When considering the entire structure of a clear 
water tank of this size, this was a fairly economical design as the thickness was extremely low. It is also pertinent to mention that the cover slab was separated from the vertical wall and therefore no bending stresses were created at the top.

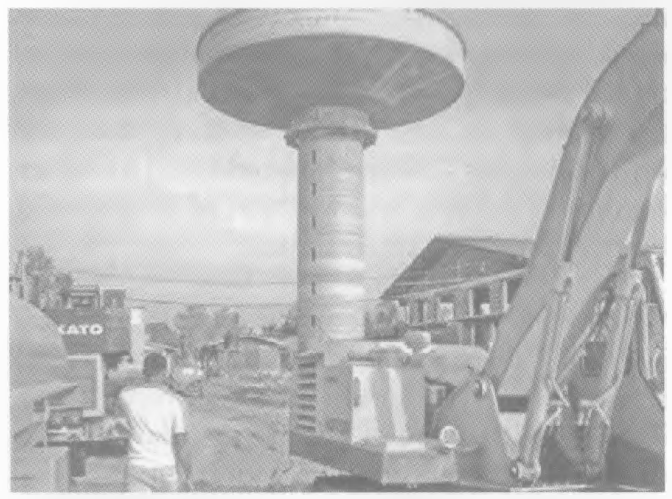

\section{COMPLETED WATER TOWER}

The high-lift pump was situated within the tank. The contractor had to have a coffer dam to prevent ingress of water during construction. The inlet diameters of the pumps were $900 \mathrm{~mm}$ in size and the same structure was used to pump water to another project which was constructed by another organization. Therefore when considering the inlet structure it had been economical to have inlet stations to provide water to two schemes at the same time.

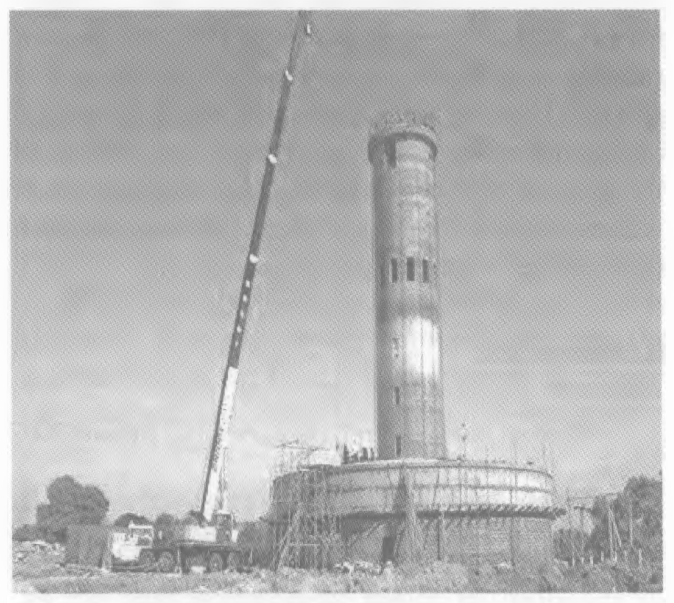

TANK BEFORE LIFTING

Since the water was drawn from an irrigation tank serving a substantial amount of cultivation work upstream, a fair amount of fertilizer is drained into the irrigation tank. As a result of this the algae content in the water was extremely high and an increased capacity sludge-holding tank was a necessity. To economize on the infrastructure it was a challenging task to design an optimum sized sludge-holding tank. Therefore, a separate tank known as a sludge thickener was built, and the wet sludge which was connected to the sludge tank was transferred to the sludge thickener which dried and substantially reduced the volume of waste which was thereafter disposed of in a dedicated area. The drained water was again recycled to the system and purified for consumption. By this process the wastage was also minimized in the cleaning process.

In the entire scheme the distribution system consisted of $57 \mathrm{~km}$ of pipe work and the transmission system consisted of $289 \mathrm{~km}$ of pipe work.

\section{Operation of the Scheme}

In this water supply scheme there were many pumping stations to augment the water supply for the purpose of distribution. These pumping stations were located at Bangalawadiya, Nintavur, Sainthamaruthu, Marthamunai, Irakkamam and Akkaraipattu. At all these locations, there were ground water sumps in capacities varying from $1,600 \mathrm{cu} \mathrm{m}$. to $2,000 \mathrm{cu}$ m., providing a dead storage for water as well as storage to pump water to elevated water tanks. By having large capacity water sumps at ground level, storage was provided in situations where the maintenance of the system extended to more than a few days. Similarly, at all these stations, there were spare water pumps to ensure pumping capacity during the maintenance of pumps. These sumps were rectangular in shape and constructed with reinforced concrete. Although the shape of these tanks had a disadvantage in the shell structures which were constructed to store clean water at the pumping station, they do have the advantage of speedy construction as the formwork is linear and straightforward.

\section{Maintenance}

In Sri Lanka, bcing a developing country where our technical know-how is not an advanced as this in developed countries, it is always preferable to have manually operated and simple schemes. Therefore, systems with pressure pumps to pressurize water distribution would involve a considerable number of pressure pumps and also skilled people to operate them. Generally, since we do not have a good maintenance record, these types of schemes have to be discouraged in place of systems featuring water towers to boost water pressure. It is a known fact that in certain projects, inappropriate design and improper 
construction have caused many operational difficulties which have resulted in the interruption of water supplies. Sustainability of a project mainly depends on its simplicity. Therefore, investing in sophisticated projects might lead to disastrous consequences if there are frequent maintenance problems.

The other reason for failure in the infrastructure has been a lack of maintenance. It is a common scene in some of the water infrastructure projects that the entire system is overgrown and covered with weeds, corroded pipelines, malfunctioning regulator apparatuses. The final result of the defects would be the wastage of the investment in the infrastructure. It is inportant to note that all infrastructure projects should have their own maintenance schedules and budget, skilled workmen and maintenance programmes. It is extremely important to adhere to the periodic maintenance programmes of these projects as it would affect the sustainability of the scheme

\section{Conclusion}

Development of water resources and implementation of infrastructure work for providing clean water is an essential requirement for the well being of the masses. Therefore, to provide this facility, firstly the government should have a clear cut policy and a target so that one could achieve these targets with determination if there is due commitment. Some of these infrastructure schemes are extremely expensive but essential as it would improve the quality of the living standards of the people. In places like Ampara where the expansion of population is considerable when compared with other parts of Sri Lanka, it is a challenge to the government to provide facilitics for an expanding population. When implementing infrastructure projects it would have an adverse impact on the environment as large areas of land have to be acquired sometimes from the people of the area if such land is not available to the government. In these water supply schemes, although there were many problems related to the acquisition of land, with the perseverance of the officers of the public service it had been possible to overcome these difficulties with the cooperation of the people. Therefore, when implementing a project of this nature, public consultation is extremely necessary as people of the area should be convinced that these projects would be beneficial to the community at large in these areas.
When compared to the water which is used for irrigation purposes, the percentage of consumption would not be more than $1 \%$ of the total volume. Therefore, under all circumstances, it is justifiable to use the water for human consumption from irrigation sources. However, there is a division among the officers concerned that drinking water supply sources should be separated from irrigation water sources. This is not a feasible option as, if that has to be done for drinking water schemes, it would add a further burden as the cost and location of land would be an enormously difficult task.

When planning water supply schemes it is not advisable to consider standard growth rates, consumption patterns etc., because these depend on the type of population that is being catered to. The growth rate in the country is not comparable with some of the districts like Ampara. Therefore this aspect as well as usage patterns which would vary depending on cultural usage, livelihood, size of land, weather patterns etc. have to be considered.

It is also important to create awareness of the users on the economic aspects of the development of water resources, scarcity of water, adverse consequences of the over-utilization of water. However, although water has become an economic commodity it is also a cultural, social and environmental requirement. Therefore it is improper to evaluate the cost benefit ratio only in terms of population as there is a great value to water in areas where it is needed and in terms of the requirement the people of these areas deserve to have clean and adequate water as their livelihood depends so much on this scarce commodity.

\section{References:}

1. Central Bank of Sri Lanka, Annual Report 2007

2. Water Resources Council \& Secretariat (2202). National Water Resources Policy and Institutional Arrangements, Colombo.

3. Zainudeen, M Y (2001), Water Resources Engineering and Management for Rural Communities, the Challenges for Agriculture and other water users in Sri Lanka in the 21st Century, "Engineer" IESL, Colombo.

4. Country Paper, National Water Resources Authority.

5. ADB News Release, 19th September, 2000. 